Постранський Т.М., Афонін М.О., Бойків М.В.

Національний університет «Львівська політехніка», Львів, Украӥна

\title{
ВПЛИВ ПРОЕКТОВАНОЇ СХЕМИ ОРГАНІЗАЦІЇ КРУГОВОГО РУХУ НА НЕРЕГУЛЬОВАНОМУ ПЕРЕХРЕСТІ МІСЬКИХ ВУЛИЦЬ НА ТРИВАЛІСТЬ ТРАНСПОРТНОЇ ЗАТРИМКИ
}

\begin{abstract}
Щорічне збільшення рівня автомобілізації призводить надмірного навантаження на вулично-дорожню мережу (ВДМ) населених пунктів. Це призводить до появи різного роду проблем соціального та економічного характеру, зокрема збільшується кількість та тривалість транспортних заторів, рівень забруднення навколишнього середовища продукцією роботи автомобільного транспорту, тривалість руху пасажирів громадського транспорту тощо. На сьогодні одним з найпрогресивніших шляхів боротьби з вищезазначеними проблемами $\epsilon$ ефективна організація руху громадського транспорту. Це дозволяє скоротити обсяги користування індивідуальним транспортом (легковими автомобілями) і, як наслідок, знизити показники існуючих транспортних потоків. Також, згідно цього постає завдання, щодо реорганізації існуючої та проектування нової ВДМ. Проте це потребує значних фінансових витрат та, часто, є неможливим у населених пунктах з історичною забудовою. Тому, у таких випадках альтернативою для покращення умов руху $\epsilon$ покращання існуючих схем організації дорожнього руху.

У роботі розглянуто один з варіантів реорганізації ділянки ВДМ, зокрема влаштування кругового руху на нерегульованому перехресті міської вулиці. Зокрема, для прикладу обрано існуюче перехрестя м. Львів. У якості програмного забезпечення для моделювання існуючих та проектованих умов руху, обрано продукт німецької компанії PTV Group - PTV Vissim. За допомогою цього програмного забезпечення встановлено вплив проектованої схеми організації на тривалості перебування транспортного засобу (ТЗ) в заторі та довжину його черги.

Ключові слова: схема організації дорожнього руху, PTV Vissim, тривалість транспортної затримку, довжина черги.
\end{abstract}

\section{ВСТУП}

Організація дорожнього руху повинна забезпечувати швидкий та аварійний пропуск учасників дорожнього руху, зокрема ТЗ, велосипедистів та пішоходів. Проте під час їх створення необхідно враховувати як планувальні параметри ВДМ, так і наявність відповідних фінансових ресурсів. Тому, чітко визначити межі цієї діяльності досить складно. На сьогодні до таких заходів відносять: створення умов першочергового пропуску громадського транспорту, каналізацію дорожнього руху, перепланування транспортних вузлів, облаштування острівців безпеки, влаштування зупинок громадського транспорту, створення системи світлофорної сигналізації, встановлення різних технічних засобів, впровадження автоматизованих систем управління дорожнім рухом тощо. Проте під час здійснення цих проектних рішень першочергово враховується безпека та зручність руху i мінімізація будь яких затримок [1]. Таким чином організація дорожнього руху та іï схеми є значним інструментом щодо врегулювання транспортних та пішохідних потоків на мережі населеного пункту.

\section{АНАЛІЗ ЛІТЕРАТУРНИХ ДАНИХ ТА ПОСТАНОВКА ПРОБЛЕМИ}

Часто в якості недоліку існуючих схем організації дорожнього руху виступають транспортні затримки в русі. Вони являють собою зниження швидкості сполучення, або часті вимушені зупинки, у порівнянні з можливими оптимальними значеннями на досліджуваній ділянці ВДМ. При цьому, необхідно зазначити, що тривала транспортна затримка часто перетворюється у транспортний затор. Це призводить до сповільнення транспортного потоку та максимального його ущільнення. Передумовою цьому часто виступає надмірне зростання інтенсивності руху [2].

На сьогодні у різних джерелах зазначаються різні поняття терміну «транспортний затор». Але в більшості випадків вони відображають явище транспортного процесу, коли інтенсивність потоку автомобілів перевищує розрахункове значення пропускної здатності автомобільної дороги чи вулиці. При цьому, із збільшенням показника інтенсивності руху спостерігається збільшення впливу автомобілів один на одного. Таким чином рухомі одиниці в щільному транспортному потоці рухаються в режимі «слідування за лідером». За таких умов автомобілі об'єднуються в групи і рухаються колонами. Така ситуація часто спостерігається на ділянках ВДМ населених пунктів 3 ускладненими елементами плану і поздовжнього профілю дороги, наявністю кривих малого радіуса, підйомів і спусків, ділянок з обмеженою видимістю, вузьких місць на проїжджій частині, перехрещень в одному рівні з проблемами в існуючих схемах організації дорожнього руху тощо [3]. 
Усі причини виникнення транспортних заторів можна розділити на дві групи чинників [4]:

- пов'язані з безпосереднім рухом транспортного потоку (мікрорівень);

- пов'язані з попитом населення на пересування (макрорівень).

Для вирішення вищезазначених проблем здійснюють проектування та удосконалення автомобільних доріг. Під час моделювання транспортних потоків головним завданням $є$ розроблення гнучкої і якісної логістичної системи міста. При цьому, вивчення дорожніх вузлів, з точки зору режиму руху, навантаження окремих ділянок та пропускної здатності, має вагоме значення $[3,5,6]$.

На сьогодні для моделювання руху можуть застосовуватися як математичні моделі (стохастичні та детерміновані), так і відповідне програмне забезпечення (PTV Vissim, PTV Visum тощо). Модулювання руху транспортних потоків на ВДМ може здійснюватися на мікро- та макрорівнях. Для локального моделювання, широкого застосування отримала програма PTV Vissim. Вона дозволяє здійснювати точне моделювання переміщення ТЗ, 3 подальшою візуалізацією результатів, за існуючих та проектованих схем організації дорожнього руху, зокрема $[5,6]$ :

- порівнювати геометрію перехрестя;

- аналізувати схеми пріоритетності громадського транспорту

- розглядати ефективність роботи світлофорної сигналізації тощо.

Ефективність транспортної мережі залежить від продуктивності характеристики різних ії складових. Тому, для підвищення ефективності схем організації руху на перехрестях, необхідно створювати імітаційні моделі які відображатимуть їх роботу. Це дозволить більш точно прогнозувати зміну параметрів руху на ньому, ніж аналітичний його опис [7]. Це дозволяє стверджувати, що для перепланування схеми перехрестя необхідно крім аналітичних розрахунків ще й створити імітаційну модель для визначення максимальної довжини черги ТЗ на всіх його підходах.

\section{ЦІЛЬ ТА ЗАДАЧІ ДОСЛІДЖЕННЯ}

Метою роботи $€$ виявлення закономірності зміни параметрів затримки у транспортному потоці на підходах до перехрестя за умови впровадження схеми організації кругового руху на нерегульованому перехресті міських вулиць.

Для досягнення вищезазначеної мети роботи, необхідне вирішення таких задач:

- провести натурні дослідження первинних показників транспортного потоку на ВДМ;

- здійснити моделювання роботи перехресть вулиць у програмному середовищі PTV Vissim за існуючої та проектованої схем організації дорожнього руху;

- визначити закономірності зміни параметрів затримки у транспортному потоці на підходах до перехрестя за існуючої та проектованої схем організації дорожнього руху.

\section{РЕЗУЛЬТАТИ ДОСЛІДЖЕНЬ}

Під транспортним дослідженням розуміють комплекс видів діяльності, при яких відбувається збір інформації про параметри дорожнього або іншого видів транспорту. Метою збору інформації $\epsilon$ отримання вихідних даних для подальшого покращення умов дорожнього руху, зокрема $[1,4,8]$ :

- планування;

- проектування;

- модернізації доріг та споруд.

Ïх необхідно проводити для збору інформації, яка дозволить здійснювати покращення умов на ділянках ВДМ, з дотриманням безпеки руху, техніко-економічних показників, впливу на навколишне середовище тощо. Особливістю методологій проведення транспортних досліджень $є$ те, що кількість завдань, які потрібно виконати на ВДМ є досить великою. Слід зазначити, що збільшення кількості сучасних засобів вимірювання дозволяе дещо зменшити трудомісткість процесу замірів показників транспортних потоків [9].

У роботі за об'єкт дослідження обрано нерегульоване Т-подібне перехрестя магістральної вулиці загальноміського значення та магістральної вулиці районного значення (рис. 1а). Заміри фактичної інтенсивності руху транспортних потоків проведено методом оперативного обліку протягом однієї години пікового періоду доби. За результатами збору інформації про інтенсивність руху транспортних засобів на досліджуваній ділянці ВДМ, отримано дані наведені на рис. 2. На основі цього створено проектовану схему кругового руху на об’єкті дослідження (рис. 1б). 


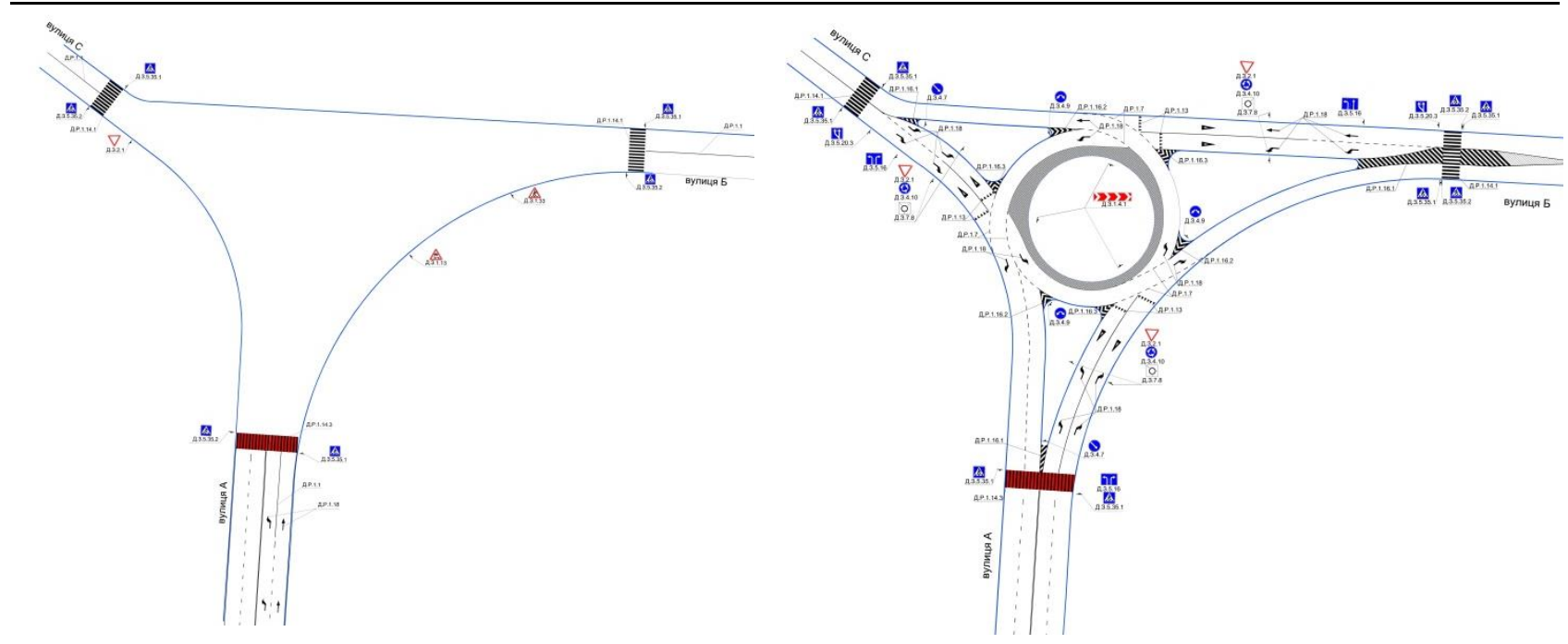

Рисунок 1. Існуюча схема організації дорожнього руху на досліджуваному перехресті

$a$

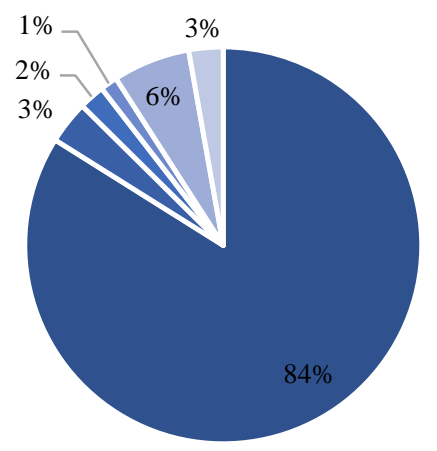

- Легкові

- Вантажні до 2 т

- Вантажні від 2 до 6 т

- Вантажні від 6 до 8 т

- Автобуси

- Тролейбуси $\sigma$

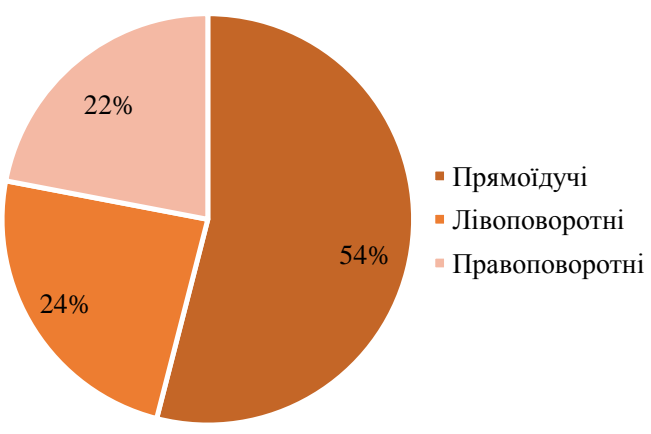

Рисунок 2. Результати дослідження складу (а) транспортного потоку та його розподіл за дозволеними напрямками руху (б)

Паралельно $з$ вищезазначеними дослідженнями проведено замір миттєвих швидкостей руху різних транспортних засобів. На основі результатів натурних досліджень, у програмному середовищі PTV Vissim створено моделі руху транспортних потоків на досліджуваному перехресті за існуючої та проектованої схем організації дорожнього руху (рис. 1). При цьому здійснено налаштування параметрів транспортних потоків (рис. 3).

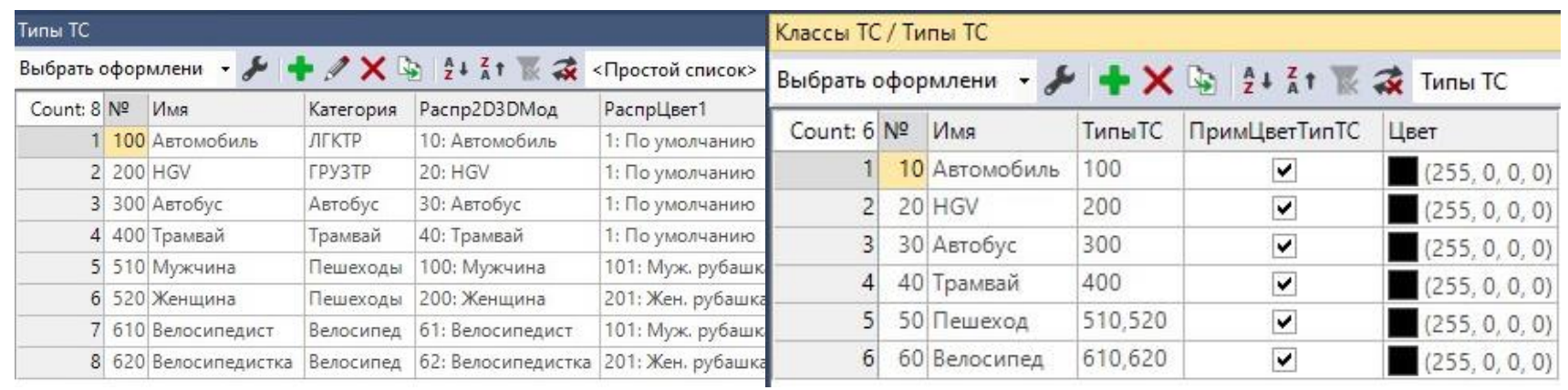

Рисунок 3. Налаштування параметрів транспортних потоків у програмному середовищі PTV Vissim

При цьому під час налаштування створеної моделі, враховується тип ТЗ, його параметри, склад транспортного потоку, розподіл за напрямками руху, дозволені маневри на ВДМ тощо. Крім цього вищезазначене програмне забезпечення дозволяе здійснювати додаткові налаштування таких параметрів [5]: 
- налаштування характеристик водія автомобіля;

- налаштування параметрів часу, що необхідний для здійснення маневрів повороту;

- відстань між автомобілями у черзі;

- пріоритет вибору водіями смуги руху тощо.

Таким чином, за допомогою програмного продукту PTV Vissim створено моделі роботи перехрестя за існуючої та проектованої схем організації дорожнього руху. Для прикладу, на рис. 4 наведено модель роботи проектованого перехрестя.

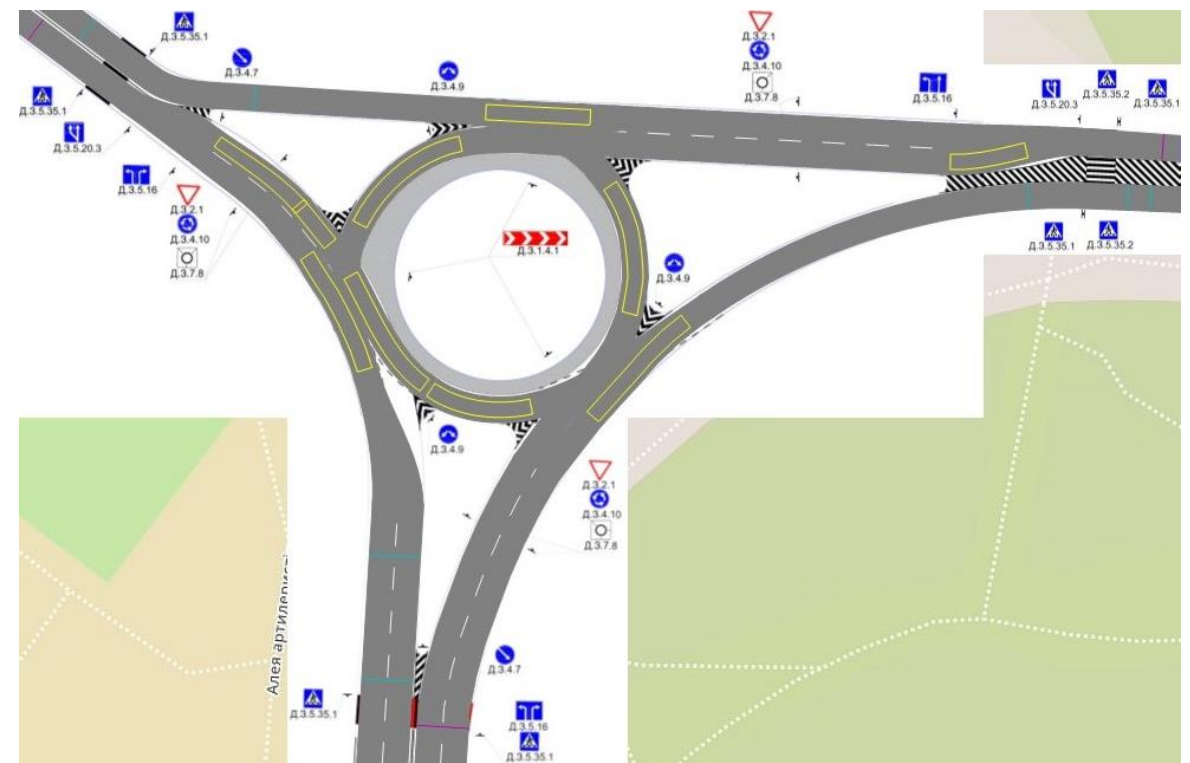

Рисунок 4. Модель проектованої схеми організації дорожнього руху на досліджуваному перехресті вулиць у програмному середовищі PTV Vissim

Під час проведення імітаційного моделювання роботи перехрестя вулиць, у програмному середовищі PTV Vissim встановлено вимірювальні пункти на усіх підходах. Вони дозволяють отримати дані показників транспортного процесу.

\section{ОБГОВОРЕННЯ РЕЗУЛЬТАТІВ ДОСЛІДЖЕННЯ}

На основі даних, які отримано шляхом проведення моделювання руху транспортних потоків у створених моделях у програмному середовищі PTV Vissim, за допомогою програмного забезпечення Microsoft Excel здійснено опрацювання результатів імітаційного моделювання. Для зручного порівняння встановлених даних, результати досліджень згруповані і подані для кожного підходу модельованого перехрестя окремо. Таким чином, на рис. 5 наведено динаміку зміни тривалості перебування Т3 в заторі, а на рис. 6 - довжини черги.

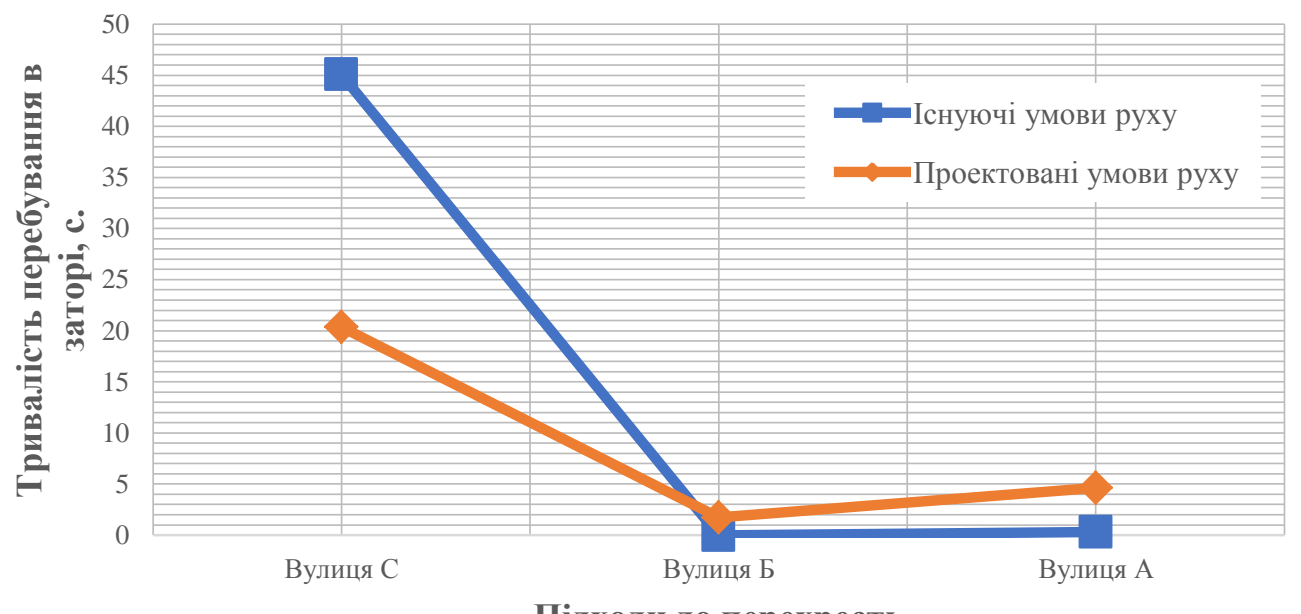

Підходи до перехресть

Рисунок 5. Результати досліджень тривалості перебування Т3 в заторі 


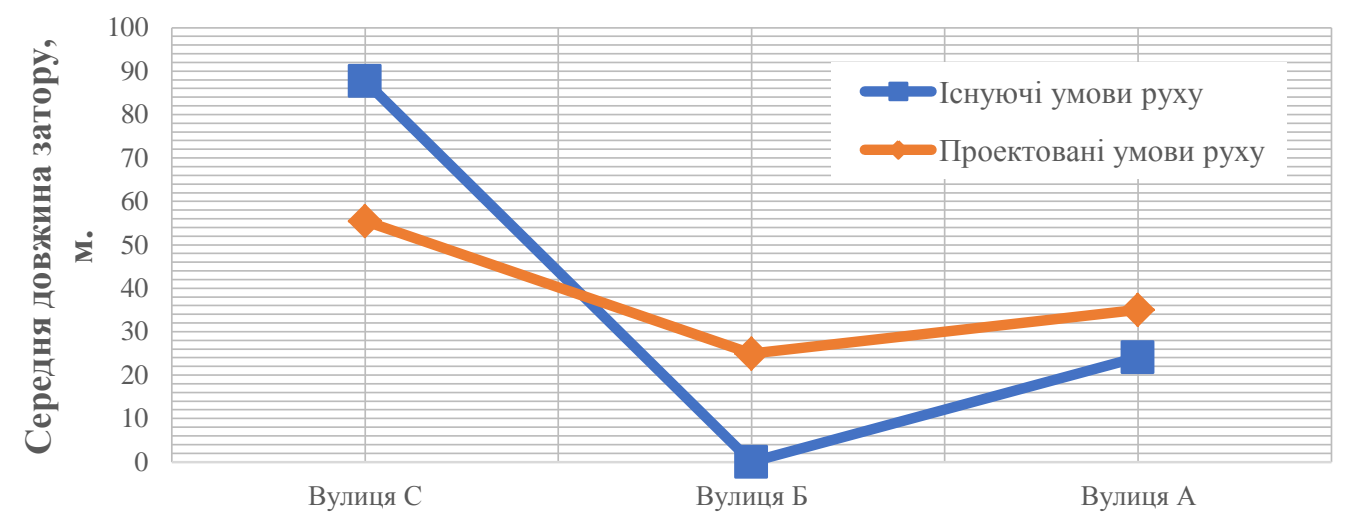

Підходи до перехресть

Рисунок 6. Результати досліджень довжини черги автомобілів за існуючої і проектної схеми ОДР на перехресті

3 графіку результатів досліджень тривалості перебування ТЗ в заторі видно, що введення проектних рішень ефективно вплинули на показники роботи перехрестя. Таким чином встановлено, що на за умови впровадження проектованої схеми руху на досліджуваному перехресті, середня тривалість перебування транспортного засобу в заторі на підході з вулиці С зменшується. При цьому, на цій ділянці вулиці середня тривалість затримки знижується з 45,07 с до 20,36 с., а середня довжина черги - 387,74 м до 52,49 м. Що стосується підходів з вулиці А та Б, то тривалість перебування в заторі дещо зростає, зокрема: 3 1,21c. до 4,62 с. та 0,34c. до 1,75 с, відповідно. Слід зазначити, що зростання середньої довжини затору на підході з вулиці А змінюється. і зростає з 24,06м. до 35,11м, а вулиці Б - 3 1,32 м. до 25,01 м. Збільшення довжини черги на підходах за напрямом А-Б пояснюється тим, що цей напрямок був головним, а після впровадження кругової схеми руху з'явилися затримки в русі, оскільки пріоритет руху має потік автомобілів, які рухаються навколо центрального острівця. Розрахувавши загальну тривалість транспортної затримки з усіх підходів до перехрестя, то вона зменшується, а швидкість руху - збільшується.

\section{ВИСНОВКИ}

1. Проведено натурні дослідження параметрів транспортних потоків з використанням фотовідео обладнання на ділянці вулично-дорожньої мережі великого міста. Перехрестя є Т-подібним та нерегульоване за схемою організації дорожнього руху. Документальним методом проведено аналіз встановлених даних та визначено склад потоку і частку транспортних засобів, які рухаються у різних дозволених напрямках. Виявлено, що за існуючого стану переважають легкові автомобілі (84 \%).

2. На основі встановлених параметрів транспортних потоків створено модель у програмному середовищі PTV Vissim за існуючої (нерегульованої) схеми організації дорожнього руху. На основі створеної моделі, здійснено проектування варіанту схеми саморегульованого перехрестя. Створення таких імітаційних моделей полягало у реальному відтворенні транспортної мережі з урахуванням геометричних та інженерних параметрів доріг за різних схем організації дорожнього руху. Під час моделювання руху на перехрестях встановлено, що кожна з цих схем руху має свої особливості і в різній мірі впливають на середню тривалість затримки транспортних засобів у потоці, яка коливалася в межах від 0,34 до 45,07 с. Така оцінка роботи перехресть дає змогу визначити основні «вузькі» місця на перехрестях вулиць за зміни основних показників транспортного потоку.

3. За результатами моделювання встановлено значення середньої тривалості затримки транспортних засобів у потоці за різних схем організації дорожнього руху на перехресті. Слід зазначити, що $з$ урахуванням генеральних планів розвитку міст часто на існуючих перехрестях передбачена зміна планувальних параметрів, зокрема облаштування розв'язок у різних рівнях. Проте враховуючи вартість цих робіт, часто такі рішення $\epsilon$ неможливими щодо впровадження 3 урахуванням можливого фінансування. Тому, в таких випадках, доцільно здійснювати моделювання руху транспортних потоків за різних схем організації дорожнього руху та різних варіантів проектних рішень.

\section{ПЕРЕЛІК ДЖЕРЕЛ ПОСИЛАННЯ}

1. Організація та регулювання дорожнього руху / [В. П. Поліщук, О. О. Бакуліч, О. П. Дзюба, В. І. Єресов та ін.] - К. : Знання України, 2012. - 467 с. 
2. Wang, Z. Visual traffic jam analysis based on trajectory data / Z. Wang, M. Lu, X. Yuan, J. Zhang, H. Van De Wetering // IEEE transactions on visualization and computer graphics. - 2013. - Volume 19 (12). - P. 2159-2168.

3. Грицунь О. М. Аналіз транспортних затримок на регульованих перехрестях 3 використанням імітаційного моделювання / О.М. Грицунь, В.А. Давосир // Автобусобудування та пасажирські перевезення в Україні : тези доповідей III-ої Всеукяраїнської науково-практичної конференції, Львів, 22-23 лютого 2018 року. - Львів : Видавництво: НУЛП, 2018. - С. $195-196$.

4. Клинковштейн,Г.И. Организация дорожного движения: учебник для вузов. - 5-е изд., перераб. и доп./ Г.И. Клинковштейн, М.Б. Афанасьев. - М.: Транспорт, 2001. -247 с.

5. Беспалов Д. Методы моделирования транспортных потоков [Електронний ресурс] / Д. Беспалов. - 2012. - Режим доступу до ресурсу: https://bespalov.me/2012/07/16/metody-modelirovaniyatransportnyh-potokov/

6. Шевчук Я. В. Імітаційне моделювання транспортних систем / Я. В. Шевчук. // International Scientific Journal. - 2016. - №1. - C. 116 - 121.

7. Sheela A. Traffic simulation model and its application for estimating saturation flow at signalised intersection / A. Sheela, I. Kuncheria P. // International Journal for traffic and transport engineering. - 2014. - №4. - C. 320-338.

8. Павлова I. О. Дослідження транспортного процесу на міських регульованих перехрестях / І. О. Павлова, В. В. Грабовець, О.М. Решетило, М. М. Курин // Міжвузівський збірник «Наукові нотатки». - Луцьк, 2014. - №46 - С. 386 - 397.

9. Степанчук О. В. Методологія підвищення ефективності функціонування вуличнодорожньої мережі міст / О. В. Степанчук - Київ, 2018. - 427 с.

\section{REFERENCES}

1. Polishchuk, V. P., Bakulich, O. O., Dziuba, O. P., Yeresov, V. I. \& et al. (2012). Orhanizatsiia ta rehuliuvannia dorozhnoho rukhu [Traffic management]. Kyiv: Znannia (In Ukrainian)

2. Wang, Z., Lu, M., Yuan, X., Zhang, J., \& Van De Wetering, H. (2013). Visual traffic jam analysis based on trajectory data. IEEE transactions on visualization and computer graphics, 19(12), 2159-2168. (In English)

3. Hrytsun, O. M., \& Davosyr, V.A. (2018). Analiz transportnykh zatrymok na rehulovanykh perekhrestiakh z vykorystanniam imitatsiinoho modeliuvannia [Analysis of transport delays on regulated intersections using simulation modelling]. Proceedings from : III-i Vseukiarainska naukovo-praktychna konferentsia "Avtobusobuduvannia ta pasazhyrski perevezennia v Ukraini" - The third All-Ukrainian scientific-practical conference "Bus construction and passenger transportation in Ukraine”. (pp. 195-196) (In Ukrainian)

4. Klynkovshtein, H. I. \& Afanasev, M.B. (2001). Orhanizatsiia dorozhnoho rukhu [Traffic management]. Moskva: Transport (In Russian)

5. Metody modelyrovanyia transportnykh potokov [Methods of traffic flows` modeling]. Retrieved from https://bespalov.me/2012/07/16/metody-modelirovaniya-transportnyh-potokov/ (In Russian)

6. Shevchuk Ya. V. (2016). Imitatsiine modeliuvannia transportnykh system [Simulation modeling of transport systems]. International Scientific Journal. Volume 1, 166-121 (In Ukrainian)

7. Alex, S., \& Isaac, K. P. (2014). Traffic simulation model and its application for estimating saturation flow at signalised intersection. International Journal for Traffic \& Transport Engineering, Volume 4(3). doi: 10.7708/ijtte.2014.4(3).06 (In English)

8. Pavlova, I. O., Hrabovets, V. V., Reshetylo, O.M., \& Kuryn, M. M. (2014). Doslidzhennia transportnoho protsesu na miskykh rehulovanykh perekhrestiakh [Study of transport process at urban controlled intersections]. Mizhvuzivskyi zbirnyk «Naukovi notatky» [Interuniversity collection "Scientific notes"], Volume 46, 386-397 (In Ukrainian)

9. Stepanchuk, O. V. (2018). Metodolohiia pidvyshchennia efektyvnosti funktsionuvannia vulychnodorozhnoi merezhi mist [Methodology for improving the efficiency of the cities`street and road network]. Kyiv (In Ukrainian)

T. Postranskyy, M. Afonin, M. Boikiv. Influence of the roundabout traffic scheme project instead of the unregulated intersection of city streets on the transport delay duration.

The increase of the motorization level in cities causes congestion of the road network (RN) of settlements. Research on the given problem is a topical task because the analysis of traffic management 
schemes speaks for the low level of traffic safety and many accidents on arterial streets and roads. It leads to the occurrence of accidents, in particular, the number and duration of traffic jams increases. Also, the increase in traffic delays increases the level of environmental pollution.

It should be noted that the important factor for increasing traffic safety concerning the aforementioned problems is an effective traffic organization at the intersections and approaches to them. This will allow reducing traffic delays in private transport and increasing the speed of public transport. Traffic intensity, capacity, volume-capacity ratio, and traffic conditions, besides the speed of movement, are the main parameters of traffic flow. That is why the design of new schemes of traffic organization or redesign of existing schemes on arterial roads should be based on the results of computer simulations of the main parameters of traffic flows. On the city RN, the expansion of the roadway is often impossible because of adjacent buildings. The alternative to the improvement of traffic conditions and the increase of safety of all road users is the change of the scheme of traffic management or redesign the intersection.

In this study, the application of the modern methods of simulation for the investigation and justification of the change of the traffic organization scheme is researched. The changes in the main parameters of traffic flow in the existing traffic management scheme at the unsignalized intersection and after a redesign of the intersection to the roundabout are investigated by the simulation. The duration of traffic delays on every approach to the intersection in different schemes of traffic management is analyzed. With the use of the simulation model, attention is paid to the necessity of the application of circular motion for the improvement of traffic conditions of urban public transport. It is established that the arrangement of circular motion at the unsignalized intersection of city street contributed to the reduction of queue length on the approaches to it. Also, the redesign of the intersection shows the reduction of traffic delay duration.

Key words: traffic management scheme, PTV Vissim, duration of transport delay, queue length.

ПОСТРАНСЬКИЙ Тарас Миколайович, кандидат технічних наук, доцент кафедри транспортних технологій, Національний університет «Львівська політехніка», e-mail: postranskyy@gmail.com. https://orcid.org/0000-0001-6120-9914

АФОНІН Максим Олександрович, кандидат технічних наук, асистент кафедри транспортних технологій, Національний університет «Львівська політехніка», e-mail: afonin.maxim91@gmail.com. https://orcid.org/0000-0001-5850-7478

БОЙКІВ Микола Васильович, кандидат технічних наук, доцент кафедри транспортних технологій, Національний університет «Львівська політехніка», e-mail bojkiv.mykola@gmail.com. http://orcid.org/0000-0002-4997-3677

Taras POSTRANSKYY, $\mathrm{PhD}$, associate professor of transport technologies department, Lviv Polytechnic National University, e-mail: postranskyy @ gmail.com. https://orcid.org/0000-0001-6120-9914

Maksym AFONIN, PhD, assistant of transport technologies department, Lviv Polytechnic National University, e-mail: afonin.maxim91@ gmail.com. https://orcid.org/0000-0001-5850-7478

Mykola BOIKIV, PhD, associate professor of transport technologies department, Lviv Polytechnic National University, e-mail: bojkiv.mykola@gmail.com. http://orcid.org/0000-0002-4997-3677

DOI: 10.36910/automash.v2i15.397 